DOI 10.37882/2223-2982.2021.04.38

\title{
СОВРЕМЕННОЕ ИНФОРМАЦИОННОЕ ОБЩЕСТВО И ЗАДАЧИ ПЕДАГОГИКИ (НА ПРИМЕРЕ АЗЕРБАЙДЖАНСКИХ КОЛЛЕДЖЕЙ)
}

\section{MODERN INFORMATION SOCIETY AND TASKS OF PEDAGOGY (ON THE EXAMPLE OF AZERBAIJAN COLLEGES)}

\section{S. Eylazova}

Summary: This article examines the relationship of the modern information society with the tasks of pedagogy (on the example of Azerbaijani colleges). As a confirmation of the defended theoretical positions, the main stages of the activities of the staff of the pedagogical college at the State University of Azerbaijan are shown. (Former educational institution named after M.A. Sabir). In the presented work, first of all, the sciences that pedagogy studies are indicated. Mainly, based on them, the author of the article lists and briefly analyzes the most important tasks that meet the needs of informatization and the latest technological requirements. The introduction of these tools into practice in the system of our proofs as a whole improves the quality of teaching pedagogical disciplines.

The focus of the author of the article turned out to be an acute discussion for our times on the teaching of pedagogical disciplines. The article runs through the idea of the fundamental impossibility of supporting lifelong education, since the foundations of the theory of pedagogy are not Talmud, but a guide to action. It, in turn, is tested, firstly, in practice (the degree of assimilation of the passed material), and secondly, it is fixed with the help of pedagogical experiments of various types. This article proves that only a metered combination of pedagogical theories with the practice of work of college students of different ages is it possible to achieve real success in work. The article is supplied with excerpts from the book "Azerbaijan State Pedagogical College under the Azerbaijan State Pedagogical University" - the only and therefore unique publication, which meticulously collected all information about the work of a large teaching staff.

Keywords: education, information society, technology, colleges, information technology tools, computerization, Internet networks.
Л юбой современный образовательный процесс по своей сути является информационным. Не только в XXI столетии, но и в более отдалённые времена он заключался в передаче-получении информации с использованием всех доступных технологических средств для каждого из исторических периодов. В самом начале статьи считаем целесообразным сказать несколько слов о том, когда ориентировочно возник сам термин «информационное общество». Учёные считают, что это произошло во второй половине 1960-х гг. в США н Японии,
Эйлазова Севиндж Джафар гызы Бакинский славянский университет sev.ka.84@inbox.ru

Аннотация: Настоящая статья посвящена взаимосвязи современного информационного общества с задачами педагогики (на примере азербайджанских колледжей). В качестве подтверждения защищаемых теоретических положений показаны основные этапы деятельности сотрудников педагогического колледжа при Государственном Университете Азербайджана. (Бывшее учебное заведение имени М.А. Сабира). В представленной работе в первую очередь указаны науки, которые изучает педагогика. Главным образом, основываясь на них, автором статьи перечислены и вкратце проанализированы наиболее важные задачи, отвечающие запросам информатизации и новейшим технологическим требованиям. Внедрение в практику работы названных средств в системе наших доказательств в целом повышает качество преподавания педагогических дисциплин.

В центре внимания автора статьи оказалась острая по нашим временам дискуссия по вопросам преподавания педагогических дисциплин. Как удаётся выяснить, их нецелесообразно сводить к непрерывному обучению в буквальном смысле слова. В данной статье доказывается, что только дозированным соединением педагогических теорий с практикой работы учащихся колледжей разных возрастов возможно добиться реальных успехов в работе. Статья снабжена выдержками из книги «Азербайджанский государственный педагогический колледж при Азербайджанском государственном педагогическом университете» - единственного, а потому и уникального издания, в котором скрупулёзно собраны все сведения о работе большого педагогического коллектива.

Ключевые слова: образование, информационное общество, технология, колледжи, информационно-технические средства, компьютеризация, Интернетсети.

когда пришло ясное понимание того, что объёмы и скорость обращения информации растут по возрастающей линии. В те отдалённые от нас годы этот процесс получил название «информационного взрыва». Причину информационного взрыва (или бума, как его еще называют) принято видеть, во-первых, в научно-технической революции, превратившей науку из источника достоверных знаний о мире в производительную силу цивилизованного общества и поставившей распространение научнотехнической информации на твёрдую индустриальную 
основу, и, во-вторых, в распространении новых технологий в полиграфии. Последнее особенно значимо для преподавания педагогических дисциплин, так как сделало возможными миллионные тиражи периодической печати, радио, многоканального телевидения и глобальных Интернет-сетей, без чего не обходится сегодня любой образовательный процесс. Причём, это относится к учебным заведениям всех типов: школ, колледжей, вузов. Под непосредственным влиянием средств массовой информации и коммуникации появилась и сформировалась также новая информационная модель мира. Этот существенный фактор определяет мировоззрение современного человека независимо от его национальной принадлежности, и, следовательно, должен приниматься во внимание педагогикой.

Однако при отмеченном появление нового информационного инструмента вносило в этот процесс коррективы, масштаб которых иногда напрямую зависел от его технологического потенциала. Часто сама идея использовать изобретение (или достижение) как вспомогательное средство для повышения эффективности преподавания различных дисциплин приводила к изобретениям в педагогике - точнее сказать, к созданию новых педагогических систем. Этот процесс имеет как свои плюсы, так и некоторые минусы.

Конечно, критическая литература о плюсах в наши дни многочисленна и достоверна. Инновационные технологии в педагогике школ, вузов, колледжей и других учебных заведений Азербайджана в последние годы существенно усовершенствовались, став важной и неотъемлемой частью образования в целом. Однако не всё так было очевидно менее полстолетия тому назад. Например, ещё во второй половине 1980-х годов многие учёные - философы, историки, педагоги, просветители технологические новшества в образовании непосредственно связывали с поступательным движением общества вообще. Вместе с тем не без основания считалось в те годы, что этот «великий скачок» в материально-технической сфере был осуществлён за счёт попрания и даже разрушения коренных человеческих и духовнонравственных ценностей. Представители разных профессий в своих трудах многократно утверждали, что цена экономических успехов оказалась слишком высокой - произошло заметное снижение значимости человека, отдельной личности. Крайне ускоренный характер развития обнажил то, что не бросилось бы заметно в глаза при более плавной и последовательной эволюции. Вскоре обнаружилась бесчеловечность прежней системы. В рамках действия её механизмов человек был представлен лишь как участник процесса производства, как хорошо отлаженный инструмент, способный обеспечить выгоду. В том числе и в области образования. Все остальные человеческие качества оказывались не нужными, мешающими функционированию системы. Социолог
Карл Ясперс по этому поводу с горечью констатировал: «Следствия этой машинизации проистекают из абсолютного превосходства механической предначертанности. Человек сам становится одним из видов сырья, подлежащего целенаправленной обработке. Поэтому тот, кто раньше был субстанцией целого и его смысла, - человек, - теперь становится средством» [5, с. 245].

Отчасти высказывания К. Ясперса и других учёных на этот счёт сохранили свою силу и до сегодняшнего дня. Только технический прогресс, который шагнул далеко вперёд по сравнению со всеми предыдущими историческими периодами, остановить нельзя. Это стало особенно заметным в педагогическом образовании в конце второго десятилетия XXI века. Показать эту картину на примере работы педагогов колледжа при Азербайджанском государственном Университете (бывшее учебное заведение имени М.А. (абира) - задача нашей статьи.

Большой коллектив этого колледжа ясно осознаёт, что в педагогических целях для удовлетворения общеобразовательных потребностей современного общества и его успешного социально-экономического развития чрезвычайно важно разумное, то есть дозированное (в зависимости от возрастного ценза обучающихся) использование ИКТ. Азербайджанские педагоги в наши дни всецело придерживаются правила, изложенного ещё в информационном меморандуме института ЮНЕСКО от 2000 года: «Впервые в истории оперативная информация, помноженная на научное знание, становятся не просто средством совершенствования современного общества, но в первую очередь также и главными продуктами его экономической деятельности. Использование ИКТ в наши дни является одним из важнейших условий дальнейшего благосостояния и социального развития цивилизованного общества. Информационная грамотность и культура являются залогом успешной профессиональной деятельности человека» [1, с. 55-56]. Основное же преимущество использования ИКТ в нынешних условиях применительно к преподаванию педагогических дисциплин в профильном колледже состоит в перенесении акцентов с традиционных способов передачи информации на более совершенные и актуальные. В этом, по нашему убеждению, заключается суть главных задач педагогики. Сформулируем и проанализируем их.

Информационно-технологические процессы, происходящие в обществе, оказывая влияние на образование, ведут к изменению основных педагогических представлений, понятий и категорий. Эти изменения в основном состоят в том, что привычные педагогические термины начинают обретать другое (побочное) значение, употребляются в ином смысле, отличном от прежнего, и одним из признаков образования конца второго десятилетия XXI века в Азербайджане является переосмысление и семантические сдвиги в классических взглядах и поня- 
тиях педагогики. Указанные процессы прежде всего отражаются на содержательной составляющей традиционного образования - знании. На этом вопросе следует остановиться подробнее, поскольку именно за знанием родители перед вузами чаще всего и приводят детей в колледж. Это заведение становится своего рода срединным, тот есть «передаточным звеном» между учёбой в средней школе и высшим образованием.

Важно подчеркнуть, что новейшие технологии ориентируют передовых педагогов колледжей на то, что современное образование не должно превращаться в способ усвоения готовых, стандартизированных и общепризнанных знаний. Нет, это прежде всего первоочередной способ информационно-технологического обмена обучающихся с окружающими их людьми, то есть такого обмена, который предполагает не только и не столько усвоение материала, но передачу, отдачу, генерирование собственной информации в обмен на полученную. Иными словами, речь идет о новом способе общения, новом способе коммуникации, а если речь заходит о коммуникации, то педагогика, объективно говоря, не может оставаться в стороне.

Современное информационное общество в первую очередь предполагает взлёт интеллектуальной культуры. Как правильно подчёркивает известный азербайджанский педагог, профессор Э. Кулиева, «интеллектуальная культура современного учащегося включает умение выполнять познавательные операции самыми различными способами, самостоятельно усваивать новые сведения из профессиональной сферы. Необходимо также, продолжает свою мысль Э.М. Кулиева, - творчески осмысливать знания, работая с принципиально новыми коммуникационно-информационными технологиями. Ныне (уточним, что статья была написана в 2004 году, но сути настоящей проблемы это не меняет - примечание наше) в процессе профессиональной подготовки специалиста упор делается на переход такой организации взаимодействия педагога и студента, при котором главный акцент переносится с обучающей деятельности преподавателя на его познающую деятельность» [3, с.218].

В связи с указанным для нас совершенно очевидно, что в одну из главных задач педагогики в век массовой информатизации и технологизации входит интенсификация интеллектуальной деятельности человека. Ставка на этот вид деятельности - панацея в деле преподавания педагогических дисциплин. Э. Кулиева, как видим, говорит о вузовском образовании, но для нас совершенно очевидно, что отмеченное ею вполне применимо и к учащимся колледжей.

Данному же процессу содействует переход от традиционных форм образования к личностно-ориентированному, чему прежде всего содействует внедрение в учебный процесс активных новейших методов обучения, приёмов и средств, мобилизующих и развивающих познавательные способности учащихся колледжей. Сюда мы относим проблемное обучение, элементы исследования, дискуссионные обсуждения, деловые игры и т.д. Некоторые из них нашли своё применение в специально организованных конкурсах или в докладах на конференциях. К примеру, ведущий педагог по информатике названного колледжа Айбяниз Асланова приняла участие в конкурсе «Обучение новым методам обучения», организованном в Школьном лицее «Ankara School» с 01.08.2018 по 01.02.2019 годы. По итогам конкурса она была признана одной из 12 лучших учителей года среди 15000 участников [6, с.156]. На наш взгляд, впечатляющая картина.

О том, насколько сильна и действенна связь педагогических дисциплин с технологическими новшествами в интересующем нас колледже, указывают следующие факты: Преподаватели первой ассоциации преподают фундаментальные и специальные науки в области математики, информатики, информационных технологий и систем.

Учителя, которые заняты проблемами современной социальной педагогики и психологии, этно-психологии, дошкольного образования и воспитания, а также вопросов, связанных с сохранением и укреплением семьи, в 2017-2019 годах частично входили в состав «Комиссии по математике и информатике». Помимо вышеперечисленных профилирующих предметов, непосредственно связанных с педагогикой, они преподают математику, информатику. «В блок дошкольного воспитания входит адаптированный для младше-классников материал по ИКТ в учебном процессе, теоретические основы начального курса математики и методики преподавания математики в начальной школе» [6, с.156-157].

В курсе лекций по «семейному и домашнему образованию» учителя колледжа «активно применяют компьютерные технологий, органично дополняя педагогическую информацию методами формирования и совершенствования элементарных математических понятий» [6, с.157]. Более того, в книжном обозрении «100» лет Колледжу» издания 2019 года (на азербайджанском языке) говорится о так называемом педагогико-коррекционном воспитании, в котором также используются ИКT.

Таким образом, ясно, что в колледже при АГУ педагогические дисциплины представляют собой расширенную базу данных системы информационных технологий. По сведениям Лятифы Алекберовой, являющейся в этом колледже председателем комиссии по предметам математики и информатики, «педагогический дисциплины тесно связаны с объектно-ориентированным програм- 
мированием, комбинаторикой в области программного обеспечения, компьютерной технологией и графикой» [6, с.158-159]. Очевидно, что анализ языков программирования, системного программирование, всевозможных современных коммуникационных инструментов, связанных с медиа-порталами, Интернет-сайтами и глобальные сетями выходят за рамки настоящей статьи. Понятно и то, что передовой педагогический опыт не может быть явлением случайным, единичным. Разумеется, он распространяется, повторяется или даже углубляется в других колледжах Азербайджана. Мы основывались на материалах данного колледжа при АГУ для конкретизации сведений. Так что в целом и общем нам важно было подчеркнуть, что такое взаимодействие в колледжах нашей республики имеет место быть.

Переход к активизирующим способам организации учебного процесса формирует навыки продуктивного обучения, развивает умения самостоятельно аргументировать собственную точку зрения, анализировать сложные ситуации, совершенствовать мышление. Всё это, бесспорно, важные и актуальные задачи, стоящие перед педагогами в наше время. Технический прогресс сопутствует их скорейшей реализации в жизнь.

Пришло время установить, какая связь между «информационным бумом» и преподаванием педагогических дисциплин в колледжах? Если говорить об основных задачах современной педагогики, то прямая и непосредственная. Поясним. Большинство учёных признаёт, что одной из главных причин возникновения информационного бума, или взрыва является именно массовое профессиональное образование. В колледжах, как подготовительной (то есть предвузовской) ступени оно нацелено на подготовку грамотных специалистов - производителей и потребителей научной и массовой информаций, что имеет кардинальное значение для перспектив развития общеобразовательной сферы в Азербайджане.

Следствием информационного взрыва стала тотальная информатизация и как следствие - технологизация светского общества и образования. Но если информационный взрыв отражает количественную сторону процессов, то, по мнению Г.Л. Ильина, «сама информатизация как производная категория от него отражает уровень организации этих процессов, а также степень развития инфраструктуры, обеспечивающей циркуляцию информации, способы её хранения, переработки и использования» [2, с.111-112]. В частности, такое положение ставит перед сотрудниками педагогических колледжей нашей республики проблему тесного согласования знаний «из учебников» со знаниями, представлениями, мнениями, которые тиражируются, главным образом, СМИ. А между ними, кстати сказать, разница весьма ощутимая. Очевидно, что разветвлённая сеть педагогических дисциплин, включающая в свой состав социальную и психологическую педагогику, должна учитывать и эту тенденцию. Необходимо напомнить, что в колледжах в зависимости от возраста обучающихся подлежит обобщению школьный педагогический опыт более раннего времени. Профессионально выверенное обобщение приводит к правильной разработке новейших методов в обучении. Эти методы или приёмы, в свою очередь, определяют основные закономерности в соответствующих областях. Следуя этой цепочке, результаты исследований внедряются и апробируются в педагогических экспериментах. Наконец, на заключительном этапе появляется реальная возможность для прогнозирования развития общеобразовательных систем.

В сущности, мы перечислили основные задачи современной педагогики. По мере сил и возможностей они внедряются в вышеназванном колледже. Они же объективно не могут быть успешно реализованы без новейшей технологии. Но применение этих средств в педагогическом процессе должно осуществляться организованно и последовательно. Так, несмотря на очевидные позитивные последствия для внедрения вышеуказанных педагогических задач в практику работы, есть в применении ИКТ и некоторые издержки. Подмечено, что последствием информационного взрыва и информатизации оказалась опасная в зародыше своём проблема так называемой дипломированной неграмотности. Мы не оговорились: речь, конечно же, не идёт о повальной неграмотности давно прошедших десятилетий. Это уже абсолютно не свойственно реалиям наших дней. На смену им пришла иная, «функциональная неграмотность». Она выражается в том, что диплом об окончании колледжа (или высшего учебного заведения) более не гарантирует способности выпускника эффективно исполнять социальные или профессиональные функции. Педагоги объясняют такого рода метаморфозы, вопервых, его собственной неспособностью воспользоваться ранее полученными знаниями, во-вторых, несоответствием приобретенных профессиональных умений и навыков ощутимо меняющейся действительности. А именно, в наш век общей информатизации и компьютеризации происходит быстрое устаревание знаний и как следствие - потеря их актуальности. Для преподавателей колледжей, призванных чаще всего подготовить абитуриентов для поступления в вузы, встаёт острая проблема не только обучения в колледже, но по истечении нескольких лет - доучивания, а, быть может, и переучивания. Так, в колледжах традиционное (точнее, конечное) образование, предполагавшее получение необходимых по программе знаний в ходе определенного периода обучения, отныне становится недостаточным для полноценной будущей профессиональной и социальной деятельности. Из года в год тем самым, несмотря на совершенствование всевозможных технических средств, наблюдается разрыв в образовании. Колледж, 
как ступень к высшему образованию, порою сдаёт свои позиции в силу того обстоятельства, что на наших глазах непрерывное образование, предполагающие получение знаний в течение всей социально активной жизни человека, подменяет собой подлинные знания. Вот почему опытные педагоги иногда изрекают: между знанием и познанием есть огромная разница. В чём она состоит?

Представим себе такую картину. Поток информации, обрушивающийся на учащихся и педагогов со страниц Интернет-сайтов, безусловно, вооружает их некоторым объёмом знаний, а если быть предельно точным, то готовыми теоретическими положениями, стандартными формулами, понятиями и т.д. Но познание не складывается из суммы механистически впитываемой информации с надёрганными фразами и цитатами. Познание - высшая ступень знаний, которая позволяет прочитанное провести через концепцию «Я-сознания» и верно воспринятое применить на практике.

Около ста лет тому назад величайший педагог А.С. Макаренко писал: «Порою результатом моего чтения тех или иных книг была основательная уверенность в том, что в руках моих никакой, собственно, ни науки, ни ясной теории нет, а теорию-то надо извлекать из суммы реальных фактов и явлений, которые происходят на глазах. Нужнее для педагогики иногда бывают не столько сами книжные формулы, сколько их анализ и немедленное к тому приводимое действие» [4, с.15].

Эти слова А.С. Макаренко не устарели и, по нашему мнению, вполне приложимы к основным задачам педагогики, которые в частности с учётом современного взлёта технологических средств, реализуются в колледжах Азербайджана. Так, в вышеназванном учебном заведении специфической особенностью новейшего подхода к преподаванию педагогических дисциплин, как удаётся выяснить, является его несводимость к обучению в буквальном смысле слова. То есть педагоги этого колледжа хорошо осознают, что невозможно представить себе образование в виде процесса непрерывного обучения, потому что в противном случае сотрудники будут лишены возможности переосмыслить фундаментальные педагогические представления, внедряя их непосредственно в работу с учащимися.

Наконец, завершить нашу статью нам бы хотелось указанием на то, что в одну из педагогических задач на нынешнем этапе входит формирование нового контингента обучающихся в колледжах, существенно отличающегося от традиционного вузовского состава. Так как педагогические предметы, как уже писали, включают в себя целый комплекс наук, то соответственно возникают и развиваются в стенах колледжей междисциплинарные исследования, которые отчетливо выявляют конфликт новой концепции образования с традиционным обучением. В последнем долгие годы была в изначальном виде заложена идея конечности, что в целом противоречит современным требованиям педагогики. Вполне естественно предположить такое обстоятельство: если обновляется контингент учащихся, то соответственно расширяется и сфера педагогической деятельности в сторону пересмотра форм и способов обучения, выходящих за рамки образования в колледжах. И как бы печально и цинично это сегодня не звучало, но в связи с угрозой пандемии корона-вируса в названном колледже и других учебных заведениях этого типа широко и многосторонне дискутируются идеи открытого и дистанционного обучения. Всё активнее также обсуждаются возможности привлечения новых информационных инструментов в целях для расширения зон контакта обучающихся колледжей с конкретно изучаемой педагогической дисциплиной. Реестр перечисленных проблем очень широк и требует дальнейших исследований.

ЛИТЕРАТУРА

1. Всемирный доклад ЮНЕСКО по делам культуры. Сборник докладов по культурному многообразию. Париж, 2000, 333 с.

2. Ильин Г.Л. Стратегия развития образования на Западе на пороге XXI века. М: Наука, 1999, 288 с.

3. Кулиева Э.М. Формирование интеллектуальной культуры будущего специалиста в стенах высшей школы // Elm və cəmiyyət. Elmi məqalələr toplusu. Bakl: BSU: Kitab aləmi, 2004, s. 217-220.

4. Макаренко А.С. Педагогическая поэма. Собрание сочинений в пяти томах. Т. І., М.: Правда, 1971, 430 с.

5. Ясперс К. Современная техника. Новая технократическая война на Западе. М.: Прогресс, 1986, 371 с.

6. ADPU-nun nəzdində Azərbaycan Dövlət Pedaqoji Kolleci. 100 il. Bakı: Təhsil Nəşriyyat-Poliqrafiya, 2019, $271 \mathrm{s.}$

(с) Эйлазова Севиндж Джафар гызы (sev.ka.84@inbox.ru).

Журнал «Современная наука: актуальные проблемы теории и практики» 